\title{
POSICIONAMENTOS CRÍTICOS E ÉTICOS SOBRE A VIOLÊNCIA CONTRA AS MULHERES
}

\author{
Benedito Medrado \\ Universidade Federal de Pernambuco, Recife, Brasil \\ Ricardo Pimentel Méllo \\ Universidade Federal do Ceará, Fortaleza, Brasil
}

\begin{abstract}
RESUMO: Neste texto realizamos um exercício teórico estudando a situação de homens que cometem violência contra mulheres. Buscando pesquisar como as pessoas se posicionam e são posicionadas em práticas de poder e jogos de verdade, pressupomos ser imprescindível compreender os recursos discursivos e não-discursivos que instauram, constroem e mantêm uma prática, no caso a de violência às mulheres. Colocamos em discussão a atenção dada aos homens autores de violência nas diretrizes governamentais, dando ênfase a Lei Maria da Penha, concluindo que temos em jogo duas direções de análises e intervenções que se imbricam: por um lado, discussões e manifestações que incluem homens e mulheres, difundindo críticas ao modelo hegemônico sexista, por meio de produções artísticas, jornalísticas, publicitárias, conferências, pesquisas etc.; por outro lado, ações de mobilização voltadas para os "agentes sociais" que já atuam nas situações de violência contra a mulher para que mudem a perspectiva de suas intervenções, dando também atenção aos homens.
\end{abstract}

PALAVRAS-CHAVE: Violência; gênero; Lei Maria da Penha; práticas discursivas.

\section{CRITICALAND ETHICAL POSITIONS}

\section{ABOUTTHE VIOLENCEAGAINST WOMEN}

\begin{abstract}
In this text, we performed a theoretical exercise by focusing our analysis on the men who commit violence against women. In order to understand how people situate themselves and are situated within empowerment practices and truth games, we think that is absolutely essential to comprehend the narrative and the non-narrative resources that install, create and maintain any given practice, such as the violence against women. The goal of the study is to discuss the attention paid to the men who commit violence considering the government policies with special emphasis to the "Maria da Penha" Law. We concluded that there are two directions of analyses and interventions that are interconnected, such as: on one hand, there are forums and demonstrations that involve men and women spreading criticisms to the hegemonic sexist model through artistic, media, publicity, conferences, research work and so on. On the other hand, there are a series of practices taking place to support the work of the "social agent", who already work with the situations of violence committed against women, in order to change their perspective of intervention so that more attention can be given to the men as well.
\end{abstract}

KEYWORDS: Violence; gender; Maria da Penha Law; discursive practices.

Este artigo é um exercício de reflexão teórica que parte do seguinte pressuposto: as maneiras como as pessoas se relacionam cotidianamente são variáveis e mutantes. Assim, longe de serem determinadas por uma natureza intrínseca ou extrínseca, acreditamos que as relações humanas são construídas e institucionalizadas, na medida em que ampliamos progressivamente a rede de nossas convivências (cf. Rose, 1998, 2001a, 2001b). Determinados conceitos ou acontecimentos que nos pro- pomos a pesquisar, portanto, nem sempre existiram, ou pelo menos não se configuravam exatamente como estão no momento atual, porque não constituem uma ordem ou estrutura universal (cf. Hacking, 1998/2001; Mello, 2006; Spink, 1999, 2004).

No campo das discussões sobre violências, em particular, nos deparamos com inúmeros argumentos que, na direção oposta da que apontamos acima, terminam levando à execução de propostas simplistas que se resu- 
mem à punição, especialmente na forma de privação da liberdade. Em uma linha alternativa, compreendemos que qualquer acontecimento, sejam os caracterizados como violentos ou não, são modos afirmativos de o ser humano viver, ainda que suas consequiências sejam indesejáveis. Assim, tratar como "não-humano" práticas violentas engendradas por seres humanos não nos parece um caminho que favorece a transformação social.

Desta forma, ao nos dedicarmos ao estudo de situações em que homens cometem violência contra mulheres, estamos em busca de práticas discursivas que fomentam e sustentam as posições antagônicas de "agressor" e "agredida", buscando ir além dos lugares e pensar os jogos discursivos que constituem essa relação.

Obviamente nem todas as práticas são exclusivamente discursivas. $\mathrm{O}$ assassinato, a violência física, psicológica e moral são acontecimentos passíveis de investigação criminal que vai em busca de uma verdade, por meio de provas materiais (registros, indícios, evidências) e testemunhais (narrativas, argumentos, etc.). Porém, nosso interesse, como psicólogos sociais, não é o de revelar "a verdade dos fatos", deixemos isso para a polícia e as instituições jurídicas. A linguagem, nesta perspectiva, não é trabalhada como meio para se chegar a uma única verdade.

Nosso foco é na linguagem como prática social, historicamente datada e contextualizada, que possibilita a circulação de conteúdos, produz efeitos e gera posicionamentos. Nosso foco é na linguagem em uso, ou seja, nas práticas discursivas (Spink, 2004).

É importante salientar que não temos dúvida de que esse tipo de violência se trata de uma situação que deveria ser eliminada ou radicalmente transformada. Porém, a forma que propomos de contribuir para o debate é ir além de atrelamentos dicotômicos, tais como: bommau, homem-mulher, agressor-ofendida.

\section{Redescrever para Libertar}

Lembremo-nos do efeito "libertador" gerado pelas discussões sobre a construção social da maternidade, postuladas pelo movimento feminista e de mulheres e pelas discussões sobre relações de gênero, especialmente a partir dos anos 60. O imperativo "ser mulher é ser mãe", que contribuiu para manter, por muito tempo, um grande grupo de mulheres no contexto doméstico e familiar e longe do mercado de trabalho, foi posto em debate, e muitas mulheres passaram a conviver com diferentes possibilidades (Novelino, 1989). Mas não podemos deixar de apontar que sua inserção no mercado de trabalho também pode ser vista como uma forma de subserviência às "regras do mercado". Ao louvarmos a passagem de uma atividade a outra, deixamo-nos transpor pela perspectiva que acaba sustentando que se a mulher não é predestinada ao lar, então é, como todos os demais humanos, fadada ao trabalho nos moldes capitalistas.

O que dizer também das situações de anorexia? Apesar de todas as discussões midiáticas sobre o assunto, acadêmicas ou não, nem o efeito questionador do exemplo acima é observado. Saber que a anorexia teve visibilidade como tal no mundo moderno a partir, principalmente, dos anos 70, que é oriunda de um estilo de vida cultuado pela moda e uma "construção social", não ajuda, como nos lembra Hacking (1998/2001), a "libertar" meninas e mulheres jovens que estão sofrendo para se manterem magras, sob condições de saúde e estratégias questionáveis. Assim, as jovens garotas não deixam de adentrar em arriscadas dietas somente por terem "consciência" de que a anorexia é uma construção social. Aqui nem o olhar crítico se faz presente.

Isso nos leva a questionar as consequiências de nossas pesquisas: adotar a perspectiva da "construção social" não promove, em si, mudanças, desfamiliarização, desterritorialidades, ações libertárias. Nesse sentido, não basta reconhecer que um acontecimento tido como "natural" é construído socialmente. As narrativas que contam a construção de uma noção (por exemplo, de que a adolescência é sempre e inexoravelmente um problema social) são práticas discursivas construídas. Porém, a perspectiva é pesquisar como essa noção passa a ser vista como algo dado, como obteve o estatuto de "verdadeira". Inexoravelmente deveremos dirigir nosso olhar para as práticas que permitem a existência de tais noções e/ou acontecimentos, que se materializam em "jogos de verdade" (Foucault, 1994).

O que buscamos pesquisar é: como as pessoas se posicionam e são posicionadas em práticas de poder e jogos de verdade. Torna-se, portanto, imprescindível compreender os recursos discursivos e não-discursivos que instauram, inauguram, constroem e mantêm uma prática. É importante entender o marco social no qual habitam essas práticas e como as pessoas as atualizam em suas vidas e em seus corpos (Butler, 1987) ${ }^{1}$. Nosso trabalho, como cientistas sociais que pesquisam práticas discursivas e não-discursivas, é exatamente estudar a dimensão performática da linguagem, ou seja, a linguagem em uso (Iñiguez, 2004).

Uma das práticas que tem tido grande visibilidade na vida social brasileira é a violência de homens contra mulheres. Mas, afinal desde tempos imemoriais, há registros, relatos, pinturas ou textos sobre o assunto. Quais as peculiaridades dessa situação nos dias de hoje? Há? Em contraponto, que práticas nossos olhares críticos e éticos nos permitem apresentar?

Fragmentos de Informações sobre Violência contra as Mulheres ${ }^{2}$

Em diferentes países da América Latina, estudos 
apontam um número significativo de mulheres que afirmam ter sido vítimas de violência física exercida por seus parceiros. Em alguns países, o percentual de mulheres que afirmou ter sido agredida fisicamente por um homem chegou a $50 \%$, enquanto que o menor percentual foi de $20 \%$ (Heise, 1994). Mais da metade de todas as mulheres assassinadas no Brasil foi morta por seus parceiros íntimos (Heise). De acordo com pesquisa da Fundação Perseu Abramo (2001), a cada 15 segundos uma mulher é agredida no Brasil e mais de 2 milhões de mulheres são espancadas a cada ano por maridos ou namorados, atuais e antigos.

Estudos realizados com homens também evidenciam situação preocupante. Em Recife, no ano de 2002, foi aplicado um questionário a um total de 170 recrutas das Forças Armadas. Na questão "Há momentos em que mulher merece apanhar?", 25\% responderam que "sim"; $18 \%$ disseram que "depende". Além disso, $18 \%$ afirmaram que "já usaram agressão física contra uma mulher" (Medrado \& Lyra, 2003). No Rio de Janeiro, foi entrevistado em 2003 um total de 749 homens, com idade entre 15 e 60 anos, dos quais $25,4 \%$ afirmaram ter usado violência física contra a parceira, $17,2 \%$ informaram ter usado violência sexual e 38,8\% afirmaram ter insultado, humilhado ou ameaçado pelo menos uma vez a parceira. O mesmo estudo revelou que visões conservadoras e tradicionais sobre o que significa ser homem estavam altamente relacionadas ao uso da violência contra as mulheres (Acosta \& Barker, 2003).

Essas pesquisas evidenciam que a violência contra a mulher não parece constituir aos olhos dos homens entrevistados um problema de saúde ou questão jurídico-legal. Essas manifestações aceitas e, muitas vezes, estimuladas pela sociedade, podem indicar portas abertas para atos violentos graves que atentam inclusive contra a vida de muitas mulheres e dos próprios homens.

Por outro lado, pesquisa encomendada pelo Instituto Patrícia Galvão (2004) ao Ibope Opinião, realizada com 2.002, pessoas de ambos os sexos, residentes em cidades de todos os estados brasileiros, apresenta informações que confirmam a preocupação da população com a violência contra as mulheres. Na pergunta "Qual destes temas mais preocupa a mulher brasileira atualmente?", $30 \%$ responderam que seria a violência contra mulher em casa, fora de casa e o assédio sexual, à frente de doenças como câncer de mama e útero (17\%), Aids e o crescimento da Aids entre mulheres (10\%) e igualdade de salários com homens (9\%). Do total de entrevistados/ as, $91 \%$ consideram muito grave o fato de mulheres serem agredidas por companheiros e maridos (entre as mulheres, $94 \%$ e entre os homens, $88 \%$ ).

A percepção da gravidade da violência contra a mulher se confirma nesta pesquisa quando se constata que $90 \%$ dos/as entrevistados/as consideram que o "agressor" deveria ser processado e encaminhado para uma reeducação.

\section{Violência de Gênero e Saúde Pública}

Na revisão bibliográfica que temos produzido sobre ações voltadas para homens no contexto da violência contra a mulher, observamos duas tendências: (a) a maior parte das publicações situa-se na área de saúde pública, e (b) uma parcela muito pequena de títulos se refere diretamente ao homem, associando o conceito de gênero quase exclusivamente às mulheres, pouco refletindo sobre questões relativas à socialização dos homens e aos processos de construção simbólica, cultural e institucional mais amplos.

No entanto, para compreender a violência de homens contra as mulheres, a partir da perspectiva crítica e ética aqui proposta, é preciso incluir análises sobre os processos de socialização masculina e os repertórios interpretativos (Potter, Wetherell, Gill \& Edwards, 1990) sobre masculinidade em nossa sociedade, na qual os homens são socializados para reprimir suas emoções, sendo a agressividade, e inclusive a violência física, formas socialmente aceitas como marcas ou provas de masculinidade. Embora nem sempre as pessoas efetuem literalmente este modelo de socialização, o que se percebe é que ele estimula uma postura destrutiva e, muitas vezes, autodestrutiva.

Como conseqüência desse modelo de socialização marcado pela forte associação entre masculinidade e agressividade/violência, grande parte dos homens tem apresentado índices de mortalidade significativamente maiores que os das mulheres, em todas as faixas etárias, bem como maior número de internações relacionadas a causas externas, especialmente relacionadas a violência.

A sobremortalidade masculina, em números absolutos e coeficientes, é uma realidade mundial para todas as idades. Além disso, com exceção das doenças próprias ou específicas do sexo, os coeficientes masculinos são maiores que os femininos para praticamente todas as causas. No Brasil, informações recentes chamam a atenção para a sobremortalidade masculina em relação a causas externas (que inclui homicídio, suicídio e acidente de trânsito) e "transtornos mentais e comportamentais" (que englobam problemas oriundos do uso de álcool e outras drogas psicoativas). Os coeficientes de mortalidade por causas externas apresentam razão de sexo entre coeficientes igual a 5,5 e os "transtornos mentais e comportamentais" registram razão de 4,2 (Laurenti, Jorge \& Gotlieb, 2005).

Em estudo amplo (Indicadores e Dados Básicos Brasil [IDB]), cujo tema central foi "Saúde do homem", publicado em 2006 pela Rede Interagencial de Informações para a Saúde (Organização Pan-Americana de Saú- 
de [OPAS], Instituto Brasileiro de Geografia e Estatística [IBGE], Instituto de Pesquisa Econômica Aplicada [IPEA], Fundação Sistema Estadual de Análises de Dados [SEADE], Ministério da Saúde), evidencia-se que os homens predominam entre os nascimentos vivos (5\% a mais de meninos, ao nascer), porém apresentam maiores índices de mortalidade em todas as idades, até os 79 anos. Além disso, a expectativa de vida ao nascer é expressivamente maior entre as mulheres. Entre 1980 e 2005, a vida média dos homens no Brasil cresceu de 59,7 para 68,4 anos. Porém, desde 1991, ela vem se mantendo 7,6 anos abaixo da média para as mulheres (IDB, 2006).

Em relação à causa de mortalidade, de acordo com essa publicação, em 2004, um total de 127.470 óbitos por causas externas foi notificado pelo Sistema de Informação de Mortalidade (SIM). Deste total, 107.032 (84\%) mortes ocorreram entre a população masculina e 20.368 $(16 \%)$ entre as mulheres.

Em síntese, as informações acima evidenciam que os homens estão colocados no contexto da violência em diferentes lugares, inclusive muitas vezes como produto-alvo de padrões de subjetividade orientados por modelos de gênero e de relações hierárquicas de poder que definem a dominação masculina sobre as mulheres. Ou seja, o mesmo sistema de poder que autoriza os homens a agirem de modo agressivo e fazer valer os seus direitos sobre as mulheres em nome da honra é o mesmo sistema de poder que os coloca em situação de vulnerabilidade. Neste sentido, o estudo referido acima (IDB, 2006) afirma a importância da realização de mais pesquisas que identifiquem questões de gênero associadas à menor procura da população masculina por serviços de saúde, assim como ao seu processo de adoecimento.

No contexto de estudos sobre adoecimento, chamam a atenção as hospitalizações masculinas e femininas que também apresentam diferenças, particularmente no que se refere às internações por lesões e envenenamento (2,32 homem para cada mulher) e por "transtornos mentais e comportamentais" (1,9 homem para cada mulher) (Laurenti, Jorge \& Gotlieb, 2005).

A implementação de mudanças no sistema de saúde, por meio da Reforma Psiquiátrica, tem demonstrado algumas possibilidades de avanços nas concepções e práticas de cuidados oferecidos aos "portadores de transtornos mentais". Um exemplo disso foi a criação dos Centros de Atenção Psicossocial (CAPS), ambientes institucionais cuja proposta fundamenta sua ação em concepções mais críticas do processo de "adoecimento/sofrimento mental", buscando preservar a singularidade e a integralidade das pessoas atendidas, bem como contemplar aspectos fisiológicos, afetivos e políticos de sua existência.

Apesar de resultados exitosos, a experiência dos Centros de Atendimento Psicossocial têm se restringido, principalmente, aos chamados "transtornos mentais clás- sicos", incluindo aí a dependência química. Pouco diálogo se percebe entre os CAPS e o atendimento a homens autores de violência, o qual tem sido desenvolvido prioritariamente por organizações não-governamentais e Delegacias da Mulher. Além disso, é preciso notar que as mudanças nos serviços de "saúde mental"” têm ignorado, na maioria dos casos, a discussão sobre as relações de gênero. Deixam, portanto, de considerar a interveniência dos aspectos da socialização e das identificações de gênero na produção e configuração dos sofrimentos e no envolvimento dos homens com episódios de violência.

Ao falarmos em promoção à saúde, a partir de uma perspectiva psicossocial, nos referimos a um processo complexo de construção cotidiana, intersubjetiva do ser humano em relação aos seus sentimentos, seu corpo, sua sexualidade e seus modos de ser. É neste contexto mais amplo que buscamos a relação entre violência e saúde. Estudo da OPAS (2003) relata que a pessoa que vive em um contexto violento, que tende à violência, também se encontra em maior risco de sofrer desordens alimentares, alcoolismo e abuso de outras drogas, estresse póstraumático, depressão, ansiedade, fobias/pânico e baixa auto-estima (Heise, Ellsberg \& Gottemoeller, 1999). Assim, não podemos pensar/atuar nesta construção cotidiana e nas suas implicações para a saúde e a violência contra a mulher, sem envolver os homens, como aponta Heleieth Saffioti (2004):

As pessoas envolvidas na relação violenta devem ter o desejo de mudar. É por esta razão que não se acredita numa mudança radical de uma relação violenta, quando se trabalha exclusivamente com a vítima. Sofrendo esta algumas mudanças, enquanto a outra parte permanece o que sempre foi, mantendo seus habitus, a relação pode inclusive, tornar-se ainda mais violenta. Todos percebem que a vítima precisa de ajuda, mas poucos vêem esta necessidade no agressor. As duas partes precisam de auxílio para promover uma verdadeira transformação da relação violenta. (p. 53).

\section{A Atenção aos Homens Autores de Violência nas Diretrizes Governamentais}

Um dos intensos debates nos últimos anos foi gerado pelo recorrente recurso à Lei 9.099/95 para julgamento de casos de violência contra a mulher. De acordo com o promotor de Justiça Danni Sales Silva (2002), a Lei $\mathrm{N}^{\circ} 9.099$ implantou um procedimento criminal penal específico na jurisdição brasileira, baseando-se em princípios da oralidade, informalidade, economia processual e celeridade. Esta lei enfatiza, sempre que possível, a conciliação ou a transação, com a reparação dos danos sofridos pela vítima e a aplicação de penas não privativas de liberdade. 
A Lei 9.099 instituiu os Juizados Especiais Criminais (JECrim) como responsáveis pelo julgamento e execução de infrações penais de menor potencial ofensivo, ou seja, "as contravenções penais e os crimes a que a lei cominasse pena máxima não superior a um ano, excetuados os casos em que fosse previsto procedimento especial". Em linhas gerais, a aplicação da Lei 9.099 possibilitou agilidade e economia no julgamento dos crimes de menor ofensabilidade social (Silva, 2002).

No texto desta lei não há nenhuma alusão específica à violência contra a mulher. Porém, tornou-se recorrente, por jurisprudência, o uso da Lei 9.099 para julgamento de casos de violência doméstica e familiar contra a mulher, considerados crimes de menor potencial ofensivo, resultando em geral em penas pecuniárias, em especial o pagamento de cestas básicas pelo autor da violência.

Debert e Oliveira, em artigo publicado na Revista Pagu, edição de dezembro 2007, faz uma breve síntese sobre a aplicação da Lei 9.099 aos casos de violência contra a mulher, a partir de outras pesquisas:

. . . pesquisa realizada no Rio de Janeiro por Kant de Lima, Amorim e Burgos (2003) mostrou uma proporção ainda maior de autores do sexo masculino e de vítimas do sexo feminino: $82,2 \%$ dos autores são homens e 79,9\% das vítimas são mulheres. Azevedo (1999), em estudo realizado em Porto Alegre, também verificou que a maioria das vítimas nos Juizados Especiais Criminais são mulheres, correspondente a $62 \%$ do total de processos observados. No entanto, chamamos a atenção para o processo de feminização no JECrim, na medida em que as vítimas nessa instituição são mulheres e são vitimadas pelo fato de serem mulheres. (Debert \& Oliveira, 2007).

Na avaliação de Debert e Oliveira (2007), a criação dos JECrim alterou a dinâmica das delegacias:

... as ocorrências registradas nas Delegacias da $\mathrm{Mu}$ lher, por exemplo, são enviadas rapidamente ao Judiciário, porque, a maioria é tipificada como "lesão corporal" e "ameaça", crimes considerados de menor potencial ofensivo que dispensam o Boletim de Ocorrência e o Inquérito Policial. Elabora-se um documento mais simplificado, o Termo Circunstanciado de Ocorrência (TCO), com o relato dos fatos e a caracterização das partes, podendo ser encaminhado, com presteza, aos juizados. (Debert \& Oliveira, 2007).

A partir da forte crítica ao uso excessivo e quase exclusivo do recurso à lei 9.099/95 para julgamento dos casos de violência contra a mulher, mais recentemente, em novembro de 2004, o Poder Executivo submeteu à apreciação do Congresso Nacional o Projeto de Lei $\mathrm{N}^{\circ}$ 4.559/04. Este projeto buscava gerar mecanismos com vistas a coibir a violência doméstica e familiar contra a mulher, nos termos do parágrafo $8^{\circ}$ do artigo 226 da Constituição Federal e dos tratados internacionais ratifi- cados pela República Federativa do Brasil; cria os Juizados de Violência Doméstica e Familiar contra a Mulher. Este projeto estabelecia medidas para a prevenção, assistência e proteção às mulheres em situação de violência, fruto de um longo processo que teve início em 2002 com a formação de um Consórcio de ONG's para elaboração de uma Lei de Violência Doméstica.

Nas disposições finais (Título VI), artigo 37, o projeto de lei destacava que o Estado Brasileiro deveria criar e promover, entre outras coisas, centros de educação e de reabilitação para os agressores. Além disso, em seu artigo 28 , o projeto dizia claramente que "compete à União, ao Distrito Federal, aos Estados e aos Municípios promoverem a adaptação de seus órgãos e de seus programas às diretrizes e aos princípios estabelecidos nesta Lei”.

A Comissão de Seguridade Social e Família indicaram a deputada Federal Jandira Feghali (PCdoB/RJ) como relatora do PL, que promoveu audiências públicas para debatê-lo. O parecer da deputada reforça entre suas propostas a obrigatoriedade da criação dos centros de educação e de reabilitação para os agressores e indicava a inclusão de parágrafo único ao art. 152 da Lei de execução penal, acrescendo pena alternativa, que torna obrigatório o comparecimento do agressor em programas de reeducação.

Em 2006, este projeto de lei foi aprovado pelo Congresso Nacional e sancionado pelo Presidente da República, na forma da Lei $\mathrm{N}^{\circ} 11.340$ - mais conhecida como Lei Maria da Penha. A partir de então, a violência doméstica e familiar contra a mulher passou a ser definida como um crime específico, gerando amplo interesse no debate público e uma transformação simbólica no conceito de violência contra a mulher que, definitivamente, deixa de ser considerada crime de menor potencial ofensivo. Do mesmo modo, altera do ponto de vista prático o cotidiano das instituições que atuam no enfrentamento da violência contra a mulher, a partir da instituição, entre outras coisas, dos Juizados de Violência Doméstica e Familiar contra a Mulher

A criação desses juizados, embora ainda não plenamente implementados, também representam mudanças estruturais na prática jurídica. Mas, diferente das Delegacias, o foco dos Juizados criados pela Lei Maria da Penha recaiu sobre a violência contra a mulher desde que de caráter doméstico e familiar. Neste sentido, Debert e Oliveira (2007) questionam:

Como será a atuação desses juizados na defesa dos direitos da mulher? Essa questão que merece atenção. É a mulher como sujeito de direitos ou são as formas esperadas no desempenho por homens e mulheres do script familiar que orientarão as decisões dos juizes? Qualquer resposta generalizante seria apressada, dada as diferenças que marcam o país e a atuação das diferentes esferas do sistema de 
justiça. Contudo, a nova lei está centrada na violência contra a mulher nas relações de conjugalidade e familiar, retirando do âmbito dessas instituições a violência impetrada contra as mulheres, pelo fato de ser mulher, nos espaços públicos, nas relações de trabalho, entre outras.

O que o texto da lei traz sobre os homens? Sendo uma medida de proteção à mulher, o texto da referida Lei tende a priorizar aspectos relativos à punição do homem, especialmente na Seção II (Das Medidas Protetivas de Urgência que Obrigam o Agressor) e Seção III (Das Medidas Protetivas de Urgência à Ofendida).

Em uma simples análise textual, nota-se claramente que a lei não apresenta em nenhum momento a palavra homem, embora a palavra mulher (ou mulheres) apareça 60 vezes. Além disso, também é possível notar que para se referir ao homem e mulher envolvidos em acontecimentos violentos, empregam-se os termos "agressor" e "ofendida": 19 ocorrências e 34 ocorrências, respectivamente.

As ações previstas para o "agressor" se destacam especialmente nos artigos 20 e 35. Seguindo o texto do Projeto de Lei $\mathrm{N}^{\mathrm{o}} 4.559 / 04$ e o parecer da deputada Jandira Feghali, descritos anteriormente, o artigo 20 determina que "Em qualquer fase do inquérito policial ou da instrução criminal, caberá a prisão preventiva do agressor, decretada pelo juiz, de ofício, a requerimento do Ministério Público ou mediante representação da autoridade policial'. Já no artigo 35 (das Disposições Finais), a Lei determina que a União, o Distrito Federal, os Estados e os Municípios poderão criar e promover, no limite das respectivas competências, entre outras coisas: "V - centros de educação e de reabilitação para os agressores". Além desses, o artigo 45 modifica a Lei de Execuções Penais, inserindo um parágrafo único ao art. 152 desta indicando que "nos casos de violência doméstica contra a mulher, o juiz poderá determinar o comparecimento obrigatório do agressor a programas de recuperação e reeducação".

Chama-nos a atenção que a Lei, de certo modo, reconhece que para intervir no contexto da violência doméstica e familiar contra as mulheres, a partir da perspectiva de gênero, é preciso e implementar ações que possam também incluir os homens. Porém as ações propostas apresentam duas lacunas: (a) não fazem nenhuma alusão explícita a trabalhos de promoção à saúde (ou promoção da equidade de gênero) com a população masculina, e (b) não há uma definição clara sobre a estrutura e organização dos centros de atendimento aos "agressores", cuja finalidade, conforme a lei, é de "educação e reabilitação" (art. 35) ou "recuperação ou reeducação".

São duas lacunas importantes, porque se referem exatamente, ainda que usando termos absolutamente questionáveis, à atenção integral que deveria ser dada ao problema, envolvendo todos os agentes sociais que fazem participam. Não é à toa que isso ocorre. Porém, antes de nos determos neste aspecto, achamos importante discutir o uso dos termos como "prevenção", "recuperação" ou "reeducação".

A Lei em análise não usa repertórios sobre "prevenção", mas poderíamos dizer que a atenção proposta aos homens tem, em última instância, a intenção de lhes sensibilizar para a situação de violência contra a mulher, buscando propor-lhes outros modos de ser que não a tradicional divisão sexista, na qual de um lado está a parte frágil e de outro a parte forte e esta pode exercer sobre a outra seu poder, inclusive na forma da violência.

Mas, o que estamos falando quando nos referimos à prevenção? Prevenir tem origem etimológica no latim (pravenire) significa dispor com antecipação, acautelar (cf. Cunha, 1998). Tanto um significado como o outro vão em direção a "antecipar-se a". No caso da violência contra a mulher, a prevenção seria, então, a aplicação de medidas que pudessem evitar o uso da violência nas relações afetivas entre um homem e uma mulher. A lei não busca isso. Apenas se dirige a esta relação para punir uma das partes, na forma exclusiva de privação da liberdade. Entretanto, constatando-se isso, perguntamos: é possível prevenir a violência? É possível estabelecer estratégias eficazes para evitar uma expressão humana, naturalizada ao longo de séculos?

Não cairemos na tentação de responder imediatamente à pergunta, porque cremos que ela pode se configurar em uma armadilha, seja a resposta afirmativa ou negativa, uma vez que imobiliza ou propõe soluções "verdadeiras". Além disso, incorreríamos na tentação de novamente, responsabilizar o homem, seja individualmente, seja como categoria fictícia (mas que origina práticas), como o responsável pela situação de violência, como fruto de suas características biológicas, "naturais". Assim, basta agir sobre ele, seja por meio de campanhas "preventivas" ou punições.

A função punitiva não logra compreender os meandros de uma relação que descamba em violência, nem serve como medida que inquiete os autores de violência impedido-os de agir com violência por medo da punição. Assim, a punição não tem ajudado na "prevenção" nem na compreensão da situação, especialmente porque a Lei universaliza as situações.

Então, uma primeira tentativa de "prevenir" não no se sentido de impedir que uma violência ocorra porque não acreditamos em soluções universais e permanentes, mas no sentido de antecipar-se seria um ato simultâneo, crítico e ético de construção de masculinidades e feminilidades menos rígidos. Ou seja, por em crisis as categorias de sexo verdadeiro ou os construtos de identidade que sevem para construir corpos tão distintos. Como afirma Butler (1987), o corpo não é matéria inerte e os atributos de gênero não são expressivos, mas performativos. Conclui a autora então que: 
se os atributos e atos de gênero, as várias maneira como o corpo mostra ou produz sua significação cultural, são performativos, então não há uma identidade preexistentes pela qual um ato ou atributo possa ser medido; não haveria atos de gênero verdadeiros ou falsos, reais ou distorcidos, e a postulação de uma identidade de gênero verdadeira se revelaria uma ficção reguladora. (p. 201).

Assim, é impossível falar de prevenção sem mencionar as discussões sobre inscrições corporais e performances de gênero. O corpo, mais do que matéria inerte, pode ser compreendido como superfície na qual são inscritas performances femininas e masculinas e, como afirma Bordo (1997), são expostos a rígido exame.

Questionar as estratégias de poder-saber que constituem nossos corpos como rigidamente e naturalmente inscritos (ou produzidos) em performances sexistas vale para as práticas institucionais, sejam governamentais ou não, práticas culturais e também as nossas práticas de pesquisa nos meios acadêmicos. Inclui, também, analisar criticamente as leis e os sistemas judiciário e penal que regulamentam práticas sexistas, prisioneiras de concepções que robustecem os modelos identitários contra os quais nos posicionamos.

Nossas análises devem descrever as relações entre estes elementos que compõem o que poderíamos descrever como o mito das inscrições corporais de gênero. Essa tarefa seria a de, parodiando Foucault (2003, p. 247), trabalhar para que "se escamem algumas 'evidências', ou 'lugares-comuns"”.

Quanto à "reeducação" ou "recuperação", devemos ter uma crítica ainda mais contundente. Cremos que essa abordagem só aumenta a intolerância para com os homens que cometem violência, uma vez que os colocamos estigmatizados como a parte "podre" da sociedade que segue saneada pelos virtuosos que os tiram de circulação para formatá-los e, posteriormente, devolvê-los ao chamado "convívio social". Além de pragmaticamente inviável (veja-se o que acontece com a maioria dos homens que passaram por sistemas penitenciários), esta proposta serve exclusivamente para fortalecer estigmas. São estigmas que se assumidos pelos homens estigmatizados os levam também a um posicionamento de não mudança e de assunção e reposição dos modos de ser agressivos. Trata-se de um jogo social difícil de ser transmudado:

... O estigmatizado e o normal são parte um do outro; se alguém se pode mostrar vulnerável, outros também o podem ... O estigma envolve não tanto um conjunto de indivíduos concretos que podem ser divididos em duas pilhas, a de estigmatizados e a de normais, quanto um processo social de dois papéis no qual cada indivíduo participa de ambos, pelo menos em algumas conexões e em fases da vida. O normal e o estigmatizado não são pessoas, e sim perspectivas que são geradas em situações sócias durante os contatos mistos, em virtude de normas não cumpridas que provavelmente atuam sobre o encontro. Os atributos duradouros de um indivíduo em particular podem convertê-lo em alguém que é escalado para representar um determinado tipo de papel; ele pode ter de desempenhar o papel de estigmatizado em quase todas as suas situações sociais, tornado natural a referência a ele... (Goffman, 1988, p. 148-149).

$\mathrm{O}$ autor de violência contra a mulher é execrado publicamente e depois convidado a voltar ao "convívio social". Vemos então que se trata de uma farsa a tal "recuperação", pois o processo que inclui a chegada do "agressor" à delegacia até a sua sentença parece contrariar a proposta seguinte à pena. Trata-se de um processo punitivo, vingativo. Depois que somos vingados com a prisão do homem "violento", aí imaginamos que se poderá "reinseri-lo na sociedade". Raramente, apostamos na criatividade destes homens para além de atos violentos.

Como refere Figueiredo (2002), baseando-se em Foucault, as antigas formas de penalidades (tais como roda, fogueira, etc.) eram dirigidas ao corpo do condenado. As formas modernas (e ainda atuais) de penalidade têm a alma do condenado como alvo. "É sobre a alma, ou subjetividades, de homens e mulheres que a microfísica do poder judicial é exercida" (Figueiredo). Nos casos de violência contra a mulher, parece, assim, reproduzir-se a ordem muito bem descrita por Foucault (1975/2001) em sua obra Vigiar e punir, na qual a prisão é compreendida como um dispositivo de poder e produtor de disciplina.

Ao mesmo tempo, diante desse panorama, tornase relevante procurar entender, mais amplamente, como a ordem de gênero, instaurada em nossa cultura, interfere na experiência de adoecimento/sofrimento de pessoas marcadas por uma ordem masculina.

A prisão ainda não se mostrou um dispositivo capaz de fortalecer o potencial de transformação humana. Ao mesmo tempo, estratégias de reeducação, readaptação ou que nome queira se dar aos processos disciplinadores (Foucault, 1975/2001) tampouco se mostraram plenamente eficazes. Pensamos, porém, que a atenção aos homens autores de violência de gênero é necessária. Para isso, devemos ultrapassar algumas resistências. A primeira seria o pressuposto de que existe uma identidade fixa e que alguém a porta como uma "essência de seu caráter", "personalidade" ou de "seu interior". O termo "agressor" é um marcador identitário que muitas vezes não permite alguma transformação ou empenho na possibilidade de mudanças nas atitudes e reações de alguém. A segunda, debruçamo-nos à exaustão sobre a situação específica de violência substituindo a "noção de com- 
portamento criminoso ou criminalizável por situação-problema" (Passetti, 2003, p. 156). Cremos que os escritos de Hacking se adequam à situação dos homens que cometem violência:

. . . há um problema quanto a tratar seres humanos como espécimes. Do ponto de vista clínico, da sala de aula, ou do antropólogo médico, os múltiplos [em nosso caso os homens que cometem violência contra as mulheres] parecem incrivelmente semelhantes uns aos outros, todos agrupados em torno do protótipo. Mas cada um é diferente: cada um tem uma história única... (Hacking, 1995/2000, p. 47).

Assim, esperamos que os "atendimentos psicossociais" não se tornem mais uma ferramenta de criminalização da situação de violência, ou castigo para os homens (quase uma "pena alternativa"), mas que permitam uma ampliação do diálogo coibido tanto pela situação de violência quanto pela aplicação da Lei.

Finalizando, temos em jogo duas direções de análises e intervenções que se imbricam. Por um lado, discussões e manifestações que incluem homens e mulheres, vulgarizando (no sentido de difundindo) críticas ao modelo hegemônico sexista, por meio de produções, artísticas, jornalísticas, publicitárias, conferências, salas de aula, pesquisas, oficinas, rodas de conversa etc. Por outro lado, ações de mobilização voltadas para os "agentes sociais" que já atuam nas situações de violência contra a mulher para que mudem a perspectiva de suas intervenções, dando também atenção aos homens.

Neste sentido, é necessário que esses agentes (pesquisadores, ativistas, profissionais de saúde, justiça e educação) não conformem suas atuações por perspectivas que tratam os homens que cometem violência como "delinqüientes", "deficientes" ou "desajustados". Os educadores, psicólogos, sociólogos, assistentes sociais, em particular, deveriam reconduzir todo esse "setor do trabalho social" (Foucault, 2003, p. 79) em um movimento que aposte na possibilidade de todas as nossas relações humanas serem colocadas em questão. Mais do que um espaço de tratamento, que seja criado um espaço de escuta. Obviamente, não é a busca de um final novelesco, feliz, mas da instauração da dúvida sobre as certezas que levaram ao acontecimento violento e às medidas jurídico-legais generalizantes. Apostamos nisso: nessas condições de circulação da diversidade para se refazer escolhas e para se contrapor à violência.

\section{Notas}

1. O conceito de atualização é bastante familiar à Antropologia. Mais recentemente, Judith Butler (1987), teórica feminista, tem empregado esse conceito para falar sobre o modo como as pessoas expressam modelos culturais de gênero em suas práticas e corpos.

2. As referências à cidade de Recife (PE) justificam-se em função de pesquisa que vem sendo desenvolvida por um grupo de pesquisadores que inclui os autores deste texto.

3. O termo "Saúde Mental" é utilizado aqui em referência ao uso corrente em pesquisas científicas e ações governamentais que abordam a promoção à saúde, em seus aspectos psicossociais.

\section{Referências}

Acosta, F., \& Barker, G. (2003). Homens, violência de gênero e saúde sexual reprodutiva: Um estudo sobre homens no Rio de Janeiro/Brasil. Rio de Janeiro, RJ: Instituto Promundo.

Bordo, S. R. (1997). O corpo e a reprodução da feminidade: Uma apropriação feminista de Foucault. In A. M. Jaggar \& S. R. Bordo (Eds.), Gênero, corpo, conhecimento. Rio de Janeiro, RJ: Rosa dos Tempos.

Butler, J. (1987). Variaciones sobre sexo y género. Beauvoir, Wittig y Foucault. In S. Benhabib \& D. Cornella (Eds.), Teoría feminista y teoria crítica (pp. 53-75). Valencia, España: Alfons el Magnànim.

Cunha, A. G. (1998). Dicionário etimológico Nova Fronteira da Lingua Portuguesa (2. ed.). Rio de Janeiro, RJ: Nova Fronteira.

Debert, G, G., \& Oliveira, M. B. (2007). "Domestic violence" and different forms of conciliation. Cadernos Pagu, Campinas, 29. Retirado em 02 mar. 2008, de http://www.scielo.br/ scielo.php? script=sci_arttext\&pid=S0104$83332007000200013 \& \operatorname{lng}=$ en\&nrm=iso

Figueiredo, D. (2002, jan./jul.). Decisões legais em casos de estupro como parte de uma pedagogia do comportamento. Revista Linguagem em (Dis)curso, 2(2).

Foucault, M. (1994). Hermenéutica del sujeto: V. 25. Genealogía del Poder. Madrid, España: La Piqueta.

Foucault, M. (2001). Vigiar e punir: Nascimento da prisão (24. ed.). Petrópolis, RJ: Vozes. (Original publicado em 1975)

Foucault, M. (2003). Estratégia, poder-saber. Rio de Janeiro, RJ: Forense Universitária.

Fundação Perseu Abramo. (2001). A mulher brasileira nos espaços público e privado. São Paulo, SP: Autor. Retirado de http:/ /www.fpa.org.br

Goffman, E. (1988). Estigma: Notas sobre a manipulação da identidade deteriorada. Rio de Janeiro, RJ: Guanabara.

Hacking, I. (2000). Múltipla personalidade e as ciências da memória. Rio de Janeiro, RJ: José Olympio. (Original publicado em 1995)

Hacking, I. (2001). La construcción social de qué? Buenos Aires, Argentina: Paidós. (Original publicado em 1998)

Heise, L. (1994). Gender-based abuse: The global epidemic. $\mathrm{Ca}$ derno de Saúde Pública, Rio de Janeiro, 10(Supl. 1), 135-145.

Heise, L., Ellsberg, M., \& Gottemoeller, M. (1999). Ending violence against women. Population Reports, 27(4), 1-43.

Indicadores e Dados Básicos - Brasil. (2006). Saúde do homem. Brasília, DF: Rede Interagencial de Informações para a Saúde. Mimeo.

Iñiguez, L. (2004). Os fundamentos da análise do discurso. In L. Ignez (Ed.), Manual de análise do discurso em Ciências Sociais (pp. 50-104). Petrópolis, RJ: Vozes.

Instituto Patrícia Galvão. (2004). Percepções e reações da sociedade sobre a violência contra a mulher. São Paulo, SP: Autor. Retirado em 10 set. 2006, de http://www.patriciagalvao.org.br

Laurenti, R., Jorge, M. H. P. M., \& Gotlieb, S. L. D. (2005). Perfil epidemiológico da morbi-mortalidade masculina. Ciência \& Saúde Coletiva, 10(1), 35-46.

Medrado, B., \& Lyra, J. (2003). Nos homens a violência de gênero. 
In Programa de Prevenção, Assistência e Combate à Violência Contra a Mulher - Diálogos sobre Violência Doméstica e de Gênero: Construindo políticas públicas (pp. 37-40). Brasília, DF: Secretaria Especial de Políticas para as Mulheres.

Mello, R. P. (2006). A construção da noção de abuso sexual infantil. Belém, PA: Editora Universitária Pioneira na Amazônia.

Novelino, A. M. (1989). A cartilha da mãe perfeita: Um discurso normatizador na psicologia de mídia. Dissertação de Mestrado não-publicada, Programa de Psicologia Social, Pontifícia Universidade Católica de São Paulo, SP.

Passetti, E. (2003). Anarquismos e sociedade de controle. São Paulo, SP: Cortez.

Potter, J., Wetherell, M., Gill, M., \& Edwards, D. (1990). Discourse: Noun, verb or social practice? Philosophical Psychology, 3(2), 205-217.

Rose, N. (1998). Inventing our Selves: Psychology, power and personhood. New York: Cambridge University Press.

Rose, N. (2001a). Inventando nossos eus. In T. T. Silva (Ed.), Nunca fomos humanos: Nos rastros do sujeito (pp. 137-204). Belo Horizonte, MG: Autêntica.

Rose, N. (2001b, jan.jun.). Como se deve fazer a história do eu. Educação \& Realidade, Porto Alegre, 26(1).

Saffioti, H. I. B. (2004). Gênero, patriarcado, violência. São Paulo, SP: Editora da Fundação Perseu Abramo.

Silva, D. S. (2002, fev.). Novas interpretações da Lei no 9.099/95, ante o advento da Lei do Juizados Especiais Criminal na Justiça Federal (Lei $n^{\circ}$ 10.259/01). Jus Navigandi, Teresina, 6(54). Retirado em 02 mar. 2008, de http://jus2.uol.com.br/doutrina/ texto.asp?id=2716

Spink, M. J. (Ed.). (1999). Práticas discursivas e produção de sentidos. São Paulo, SP: Cortez.

Spink, M. J. (2004). Linguagem e produção de sentidos no cotidiano. Porto Alegre, RS: Editora da Pontifícia Universidade Católica do Rio Grande do Sul.

Benedito Medrado é professor do Departamento de Psicologia e do Programa de Pós-Graduação em

Psicologia da Universidade Federal de Pernambuco.

Doutor em Psicologia Social pela Pontifícia

Universidade Católica de São Paulo. Um dos fundadores do Instituto Papai e atual coordenador do

Núcleo de Pesquisas em Gênero e Masculinidade (cadastrado no CNPq desde 1998). Integra a Rede Feminista Norte-Nordeste de Estudos e Pesquisas sobre a Mulher e Relações de gênero (REDOR), a Rede

Brasileira de Pesquisas em Violência, Saúde, Gênero e Masculinidades (VISAGEM), a Associação Brasileira de Psicologia Social (ABRAPSO), Associação Brasileira de Saúde Coletiva (ABRASCO), a Rede Brasileira de

Homens pela Eqüidade de gênero. Coordena a Campanha Brasileira do Laço Branco (Homens pelo fim da violência contra a mulher). Endereço para correspondência: Rua Mardônio de A. Nascimento, 119, Bairro Várzea, Recife, PE, 50741-380. Tel.: (81) 32714804. beneditomedrado@uol.com.br

Ricardo Pimentel Méllo é professor do Departamento de Psicologia e do Programa de Pós-Graduação em

Psicologia da Universidade Federal do Ceará. Doutor em Psicologia Social pela Pontifícia Universidade
Católica de São Paulo. Autor do livro "A construção da noção de abuso sexual infantil". Endereço para correspondência: Rua Tancredo de Souza Carvalho, 90, Bairro Edson Queiroz, Fortaleza, CE, 60835-170.

Tel.: (85) 32735975. ricardo_pm@uol.com.br

\section{Posicionamentos Críticos e Éticos sobre a Violência contra as Mulheres}

Benedito Medrado e Ricardo Pimentel Méllo

Recebido: 25/09/2007

$1^{a}$ revisão: $17 / 03 / 2008$

Aceite final: 20/03/2008 